\title{
El cómic en ELE: una experiencia para la enseñanza de Geografía de España
}

\author{
NURIA HERNÁNDEZ LÓPEZ \\ Universidad Rovira i Virgili \\ nuria.hernandez@estudiants.urv.cat
}

\begin{abstract}
Resumen: Se presenta una actividad de innovación vinculada al uso del cómic para la enseñanza de contenidos de geografía, en el marco de un curso de Lengua Española y Cultura Hispana, destinado a estudiantes universitarios extranjeros. La actividad propuesta se basa en el uso de Pixton, una herramienta que permite crear cómics en línea. La experiencia se llevó a cabo de forma cooperativa en un Taller de Geografía de España. Tras analizar más de 40 herramientas TIC para la creación de cómics, se seleccionó Pixton y se diseñó una actividad y un material específico de apoyo para su puesta en práctica en el aula de E/LE. Los resultados obtenidos con esta experiencia demuestran que la herramienta, la metodología y el material creado son adecuados y contribuyen al aprendizaje del español y la cultura hispana, en concreto aquellos contenidos vinculados con Geografía de España.
\end{abstract}

Palabras clave: innovación, TIC, cómic en E/LE, Pixton en Geografía.

\section{The comic in the SFL: an experience for teaching Geography of Spain}

Abstract: This paper presents an innovation activity linked to the use of the comic for teaching of geographical contents within the framework of a Spanish Language and Hispanic Culture course aimed at foreign university students. The proposed activity is based on the use of the Pixton, a tool which allows creating comic online. The activity was carried out in a cooperative way, in a Workshop of Geography of Spain. After selection more than 40 ICT tools for comics design, Pixton was selected and an activity was designed, and specific materials of supporting were created for its implementation in $\mathrm{E} / \mathrm{LE}$ classroom. The results of this experience show that the tool, the methodology and the material created are adequate, and they contribute to the learning of Spanish, and the Hispanic culture, in particular those related to geography contents of Spain.

Key words: innovation, ICT, comic in E/LE, Pixton in Geography.

\section{Introducción}

Este artículo presenta, por una parte, una investigación que tiene como objetivo comprobar la efectividad del cómic como recurso para la enseñanza de contenidos de geografía, en el marco del Taller de Geografía de España, organizado por el Servicio de Idiomas de la Universidad de Murcia, incluido en el curso Lengua Española y Cultura Hispana, destinado a estudiantes universitarios extranjeros. El curso se realiza en 300 horas y consta de tres módulos: los dos primeros son de Lengua Española y el tercero es de Lengua y Cultura Española. En este último, se incluyen talleres de Geografía de España, junto a otros del ámbito de las Ciencias Sociales: Historia de España, Arte Español, Política y Sociedad Española. Este curso tiene como finalidad ampliar los conocimientos de español de los participantes y acercar a los estudiantes al entorno 
sociocultural español, dotándoles de las herramientas lingüísticas necesarias para desenvolverse en la vida cotidiana, universitaria y profesional. Por otra parte, este artículo presenta la actividad que ha servido para conseguir los objetivos de la investigación.

Los participantes de la investigación son estudiantes universitarios de entre 19 y 21 años, procedentes de China (10), Suecia (1) y Estados Unidos (9), con un dominio del español que variaba entre el B1 y el B2. También participó en la investigación la profesora titular del Taller.

Para lograr el objetivo mencionado, se seleccionó una de las más de cuarenta herramientas analizadas destinadas a la creación de cómics, y se diseñó una propuesta didáctica relacionada con los objetivos y los contenidos del Taller de Geografía de España.

\section{Marco teórico}

\section{1. ¿Qué entendemos cuando hablamos de cómics?}

El cómic se define como «ilustraciones yuxtapuestas y otras imágenes en secuencia deliberada con el propósito de transmitir información u obtener una respuesta estética en el lector» (Ortiz Moya 2009: 1). Esta es la definición más extendida, aunque no es aceptada por todos, ya que además se considera que el cómic incluye el llamado humor gráfico. La Real Academia Española de la Lengua (2017) le atribuye dos significados: «serie o secuencia de viñetas que cuenta una historia» y «libro o revista que contiene cómics». Por su parte, Lorente define cómic con las siguientes palabras:

El cómic es un bello panorama de dibujos, grafismos o juego de colores, porque mediante el prodigioso fenómeno sinestésico, el cerebro humano interpreta los mensajes icónico-visuales como recibidos por otros umbrales sensitivos: gusto, tacto, olfato u oído. Y lo hace con tal eficiencia que el lector de imágenes puede vivir el tema ofrecido como historieta con todo tipo de transferencias de sensaciones, sueños y fantasías. Por lo tanto, si el Cómic puede dar una riquísima información, es porque posee una estructura poderosa, cuya singularidad es manifiesta

Lorente Rebollo (1990: 141)

\subsection{El cómic en $\mathrm{E} / \mathrm{LE}$}

El uso del cómic como recurso en la enseñanza del español como lengua extranjera está incluido en las recomendaciones del Marco Común Europeo de Referencia para las lenguas (MCER) y puede ser un recurso igual de válido que el resto de los que aparecen indicados, para diferentes actividades con diversas finalidades. Igualmente, este recurso aparece en el Plan Curricular del Instituto Cervantes (PCIC) (2008), como parte de la lista alfabética de géneros de transmisión oral y escrita en el nivel B1 y B2, y en los niveles $\mathrm{C} 1$ y $\mathrm{C} 2$ en los géneros de transmisión escrita.

El cómic puede ser valorado como un recurso adecuado para trabajar diferentes aspectos de la lengua por sus componentes visuales y textuales. En la clase de español puede ofrecer actividades muy variadas, con objetivos lingüísticos y culturales, en las que se desarrolle la creatividad y la imaginación del alumno por ser «un soporte dinámico para el aprendizaje que aúna en un espacio limitado muchas áreas (gramática, pragmática, sociolingüística, etc.)» (Villarrubia Zúñiga 2009: 79). 


\subsection{Las TIC y el cómic para la enseñanza de Geografía de España en E/LE}

Existe una gran cantidad de materiales que solo necesitan ser dotados de sentido didáctico para la enseñanza. Este es el caso del cómic, un recurso con múltiples posibilidades a través de apps, webs especializadas y propuestas de actividades. Nos permite introducir aspectos lingüísticos y culturales, dentro del enfoque orientado a la acción propuesto en el MCER. Así, Jiménez, Mora y Cuadros afirman que:

Las TIC suponen un aumento del interés del alumno por el aprendizaje de segundas lenguas, lo que contribuye a su motivación y creatividad; un impulso del aprendizaje autónomo, mediante el cual el alumno tiene la capacidad de elección y se le otorga una autonomía en el proceso de aprendizaje; y un acceso no lineal a la información y el protagonismo del alumno en cuanto a la adquisición de nuevas lenguas

Jiménez, Mora y Cuadros (2016: 211)

\subsection{Necesidad de innovación}

«La innovación depende de tres procesos estrechamente relacionados: la imaginación, tener la capacidad de tener ideas y concebir hechos; la creatividad, para que ideas sean originales y tengan valor; y la innovación, para llevar a la práctica ideas originales» (Robinson 2017: 91). Son necesarios recursos para que fomenten el descubrimiento. En este sentido, la buena utilización del cómic resulta muy favorable para el desarrollo y la interacción de las cuatro destrezas lingüísticas, ya que es un recurso polivalente capaz de generar un aprendizaje significativo, dinámico, motivador y lúdico que nos sirve de elemento detonador. «Hay que encender primero la emoción. Todo esto debe llevar a crear métodos y recursos capaces de evocar la curiosidad en los alumnos por aquello que se explica» (Mora Teruel 2016: 27).

La enseñanza y didáctica de la Geografía cuenta con un gran número de recursos para propiciar la investigación y el descubrimiento. El área de Geografía demanda un cambio en la didáctica de forma que se adapte al contexto académico actual, optando por teorías del aprendizaje más amplias para evitar la pasividad de los alumnos con los métodos unidireccionales (Luque y Navarro 2011: 52-58). En relación a ello, la creación de cómics con el uso de una herramienta digital como Pixton, acompañada de actividades de aprendizaje como la que se plantea en esta investigación, son buenas opciones que cumplen con las condiciones que apuntan Mora (2016) y Luque y Navarro (2011).

\section{Estudio}

\subsection{Preguntas de investigación y objetivos}

Partiendo de las bases teóricas planteadas en los epígrafes anteriores, se llevó a cabo el estudio surgido de las siguientes preguntas de investigación: (1) ¿hasta qué punto sirve la creación de un cómic en línea para aprender lengua y geografía en clase de E/LE?; (2) ¿qué herramientas existen para crear cómics en línea y cuál de ellas es la más adecuada para lograr nuestros objetivos?; (3) ¿qué tipo de actividades servirían para lograr los objetivos de aprendizaje con el uso de la herramienta elegida?; (4) ¿cómo aceptará y valorará la profesora a cargo de la asignatura la implementación de esta metodología de enseñanza? 
Habiendo establecido estas preguntas planteamos los siguientes objetivos: (1) demostrar que el cómic puede ser una herramienta válida y efectiva para el aprendizaje de la lengua y de la geografía, por parte de estudiantes de español como lengua extranjera; (2) seleccionar la herramienta más adecuada para implementar una propuesta didáctica, para la enseñanza-aprendizaje de la geografía de España en una clase de español como lengua extranjera; (3) crear actividades concretas para lograr los objetivos de aprendizaje de geografía del Taller de Geografía de España; (4) corroborar la aceptación y valoración de los resultados de aprendizaje y motivación de los estudiantes por parte de la profesora al cargo de dicho taller.

\subsection{Metodología}

Se optó por una investigación de campo nomotética, entendiéndose investigación de campo la llevada «a cabo en situaciones educativas o sociales de forma natural» y como investigación nomotética aquella que permite «establecer leyes generales por las que se rigen los fenómenos educativos, propia de la experimentación» (Nieto Martín 2010: 88).

En este sentido, la investigación es de carácter mixto combinando métodos cuantitativos y cualitativos. Para ello, se utilizaron cuestionarios dirigidos a los alumnos y la profesora del curso, el diario de clase para recoger información durante la sesión los propios trabajos para obtener información sobre la aplicabilidad de la actividad y la herramienta, como un buen planteamiento para aprender español.

El primer paso para llevar a cabo el estudio fue la selección de la herramienta TIC que se considerase más adecuada para llevarla al aula con las actividades propuestas. Para ello, se realizó un análisis de los recursos disponibles en Internet teniendo en cuenta los siguientes ítems: 1. Original/clásica, 2. Compatibilidad, 3. Diseño de avatares, 4. Expresiones, 5. Movimientos, 6. Diferentes complementos (aparte de características físicas), 7. Completa/simple, 8. Sencilla/complicada de utilizar, 9. Opciones al finalizar el trabajo, 10. Registro, 11. Gratuita/pago/versión de prueba/precio, 12. Ventajas, 13. Desventajas, 14. Idiomas, 15. Creación de imágenes/permite dibujar, 16. Tipo de imágenes o dibujos, 17. Subir imágenes, 18. Tipo de público, 19. Plantilla imprimible de planificación, 20. Efectos especiales, 21. Filtros, 22. Sonido/grabación de voz/incluir música y 23. En línea/no en línea.

Estos ítems posibilitaron recoger la mayor información posible para seleccionar la herramienta que más opciones ofrece al diseño, planificación y desarrollo de la actividad. De las cuarenta y cuatro herramientas minuciosamente analizadas, finalmente se eligió Pixton.

Esta es una herramienta educativa en línea y en español con un salón virtual muy completo e intuitivo, que permite subir imágenes propias para crear los cómics, ofrece muchísimas opciones para su caracterización y múltiples posturas y movimientos, incluye un gran número de objetos y accesorios para incorporar a las viñetas, se pueden incluir grabaciones de voz, archivos de música y enlaces web en los bocadillos de diálogo o en las cartelas y permite realizar cómics de forma muy cómoda. 


\subsection{Descripción de la propuesta didáctica con el uso de Pixton}

La propuesta didáctica llevada a cabo en el aula titulada "Lugares mágicos de España" consta de una actividad con Pixton y de una serie de materiales específicos de apoyo. En los siguientes apartados vamos a describir con detalle los objetivos de dicha actividad y su aplicación.

\subsubsection{Objetivos de la propuesta didáctica}

El objetivo general de esta actividad es favorecer el aprendizaje del español como lengua extranjera en un Taller de Geografía de España, incluido en un curso universitario de español. Para ello, tal como se ha expuesto, utilizamos Pixton, un recurso para la creación de cómics en línea. El objetivo general anteriormente descrito se desglosa en los siguientes objetivos específicos:

1. Aprender y utilizar aspectos lingüísticos y vocabulario específico, relacionados con el relieve de Murcia y España en general.

2. Conocer y ubicar diferentes paisajes de España en mapas de relieve (se incluye el Estrecho de Gibraltar por estar situado en la Península Ibérica y por su interés natural).

3. Fomentar la interacción entre los alumnos mediante la actividad, para propiciar la expresión oral en español, a través del trabajo por grupos cooperativos en clase.

4. Crear historias de cómics para desarrollar la expresión escrita, la creatividad y comprensión de los términos utilizados, relacionándolos con las imágenes de los paisajes incluidos en las viñetas de los cómics realizados a través de Pixton.

5. Adquirir conocimientos de relieve y biodiversidad de lugares de España.

6. Aprender y contextualizar expresiones idiomáticas relacionadas con el clima.

7. Familiarizarse con el vocabulario básico propio de los elementos del cómic.

8. Demostrar que con la metodología y material propuesto se puede motivar y favorecer el aprendizaje de Geografía y despertar el interés por lugares de España, poco conocidos por la mayoría de los alumnos extranjeros.

\subsubsection{Metodología (temporalización, agrupamientos y material)}

La metodología tiene como principio básico la participación activa y cooperativa y el papel de las profesoras como guía, durante la sesión de 90 minutos del Taller de Geografía de España, empleando el periodo de prueba de 15 días que ofrece Pixton para Escuelas.

En cuanto a los agrupamientos, se consideró necesario realizar actividades de forma cooperativa, por los beneficios que este método de trabajo aporta a los alumnos. Pujolàs (2012: 101-103) resalta la importancia de realizar trabajos en grupo, ya que estos permiten que los alumnos cooperen ayudándose en su proceso de aprendizaje. El trabajo 
cooperativo posibilita, además, desarrollar las destrezas lingüísticas, aspecto fundamental en los cursos de español como lengua extranjera.

Para su desarrollo, además de utilizar la herramienta Pixton, fue necesario una serie de material complementario que yo misma diseñé.

Por un lado, una carpeta de trabajo que incluye: un documento con los pasos para entrar en Pixton y el código de acceso, hoja de planificación y pasos para elaborar un cómic, un documento con imágenes del relieve y paisajes de Murcia y otro de España, ambos con otros con las descripciones correspondientes, una hoja con el vocabulario básico del cómic en español, mapa del relieve de Murcia con los números correspondientes a las imágenes y las descripciones, mapa del relieve de España con los números correspondientes a las imágenes y las descripciones, y hoja de expresiones idiomáticas sobre el clima.

Y, por otro, un pendrive con tres carpetas: una con todos los documentos que se acaban de enumerar, otra con las imágenes del documento de Murcia, y la tercera con las imágenes del documento de España -estas dos últimas, incluyen las fotografías numeradas y nombradas, tal como aparecen en los documentos de las imágenes y las descripciones, para que los alumnos las pudieran localizar fácilmente en el momento de subirlas a Pixton-.

\subsubsection{Desarrollo}

Al inicio de la clase, creando un clima ameno se siguió la siguiente dinámica: a) se agruparon por grupos de cuatro y se les explicó en qué iba a consistir la actividad, entregándoles la carpeta de trabajo con el material y el pendrive; b) se les indicó cómo entrar en Pixton a través del código, hasta que accedieron al salón de clase virtual y se situaron para comenzar a crear sus cómics; c) durante el proceso de planificación, los alumnos eligieron el argumento, los personajes, los momentos más relevantes de la historia e incluyeron los bocadillos de diálogo, pensamiento y onomatopeyas, utilizando la hoja de planificación y los pasos para elaborar un cómic; d) cuando los alumnos ya tenían decididas sus imágenes y la historia, comenzaron a investigar y utilizar Pixton para plasmarla, e) diez minutos antes de finalizar la clase, aunque no pudieron terminar del todo sus cómics, los guardaron y los enviaron a la profesora a través del salón de clase virtual; f) y, para concluir, se les pidió que visitaran los trabajos de los compañeros y que explicaran y valoraran aquello que más les había gustado de cada uno.

Realizaron cómics muy diferentes, con muchos lugares e información, utilizaron vocabulario específico, sintetizaron aspectos que aprendieron, hicieron uso de la lengua para plasmar sus ideas, llegaron a acuerdos en grupo, realizaron la planificación y eligieron las imágenes entre las sesenta y ocho posibilidades existentes, y aprendieron a contextualizar expresiones idiomáticas sobre el clima incluidas en el material complementario.

La figura presentada a continuación (figura 1) es un fragmento de un cómic realizado por uno de los grupos cooperativos: 


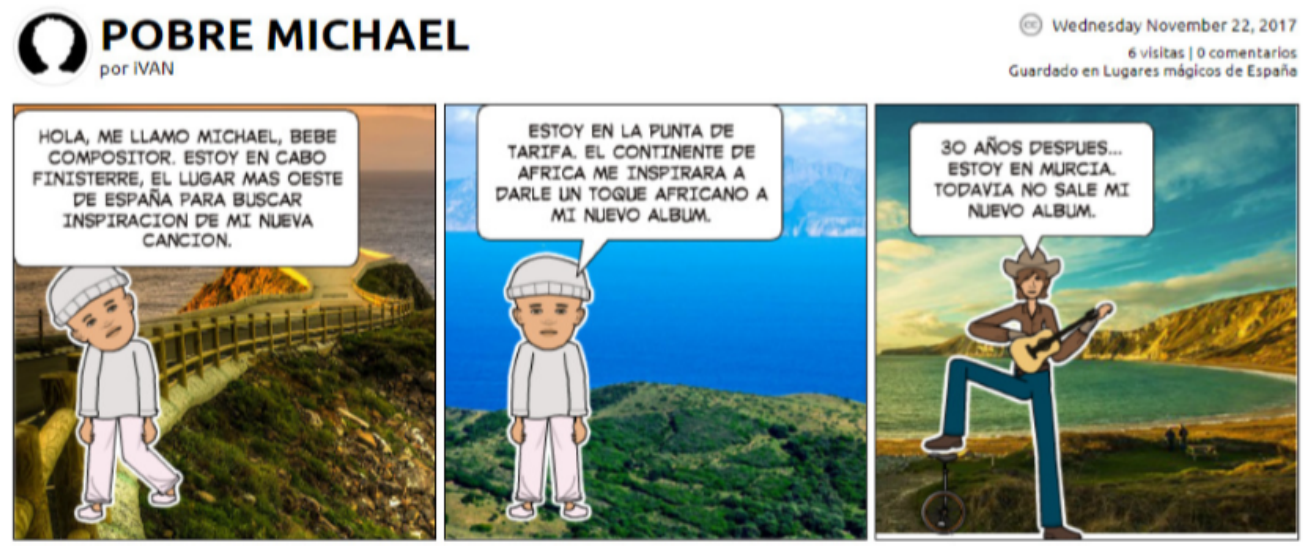

Figura 1. Fragmento de cómic realizado por grupo cooperativo

\subsubsection{Evaluación de la propuesta didáctica}

La evaluación se planteó a modo de coevaluación, exponiendo sus cómics y visitando los diferentes grupos, valorando sus trabajos en una plantilla del 1-10. Practicaron la expresión y comprensión oral de forma improvisada al argumentar sus valoraciones y al explicar a los demás compañeros los cómics que habían creado. Los trabajos también fueron valorados por la profesora del curso como parte de la nota del trabajo de clase.

\section{Análisis de resultados}

En una sesión posterior, los alumnos realizaron un cuestionario final para valorar la actividad, el material y la actuación de la profesora. Igualmente, se entregó un cuestionario final a la profesora del curso, para conocer su percepción después de realizar la actividad y su valoración. A continuación, se destacan los resultados obtenidos sobre la actividad y el material por parte de los alumnos.

\subsection{Sobre la actividad}

Los valores relacionados con la percepción del grado de aprendizaje sobre vocabulario de geografía y aspectos de diferentes lugares de Murcia y España, en general, son muy positivos.

\subsubsection{Resultados sobre el aprendizaje de los contenidos de lengua y geografía}

La mayoría de los estudiantes valoró positivamente la experiencia para el aprendizaje de lengua y geografía, siendo los valores más bajos los relacionados con la comprensión escrita y los más altos aquellos relacionados con los contenidos de geografía. A continuación, presentamos los resultados más detalladamente:

Un $65 \%$ de los participantes afirma haber aprendido mucho (40\%) o muchísimo (25\%) acerca de los lugares que aparecen en la actividad, mientras que el 30\% valoró haber aprendido bastante. 
Es muy destacable que el $90 \%$ de los participantes valorara como muy útil el uso de los mapas para aprender dónde se ubican geográficamente los diferentes lugares, un $45 \%$ dijo haber aprendido muchísimo y el otro $45 \%$ dijo haber aprendido mucho.

En cuanto a la percepción de haber practicado la expresión y comprensión oral al trabajar en grupo, un $50 \%$ de los estudiantes valoró muy positivamente entre mucho (40\%) y muchísimo (50\%), mientras que por su parte un $30 \%$ consideró que bastante.

El 65\% de los estudiantes valoró positivamente la práctica que hicieron de comprensión escrita, aunque esta valoración fue un poco inferior a la comprensión y expresión oral, ya que solo el $20 \%$ pensó que había practicado la comprensión escrita mucho (10\%) o muchísimo (10\%) y un 45\% consideró que bastante. Sobre la práctica de la expresión escrita al realizar la actividad, el $80 \%$ consideró que la había practicado, de ellos un $10 \%$ valoró haberla practicado muchísimo, un $25 \%$ mucho y un $45 \%$ bastante.

La valoración del aprendizaje de expresiones idiomáticas sobre el clima también obtuvo resultados positivos. El 80\% consideró que había aprendido estas expresiones en las siguientes proporciones: muchísimo (15\%), mucho $(35 \%)$ y bastante $(30 \%)$.

\subsubsection{Resultados sobre la metodología de trabajo}

En cuanto a la valoración de la metodología de trabajo, podemos decir que esta fue también muy positiva.

Valorando el grado de creatividad de la actividad, de nuevo el $90 \%$ de la clase la percibe como tal: el $60 \%$ consideró que lo es muchísimo y el $30 \%$ que mucho. El $75 \%$ de los estudiantes valoró positivamente el trabajo en grupo: el $45 \%$ de los alumnos contestó que le gustó muchísimo y el 30\% que mucho.

\subsubsection{Resultados sobre la valoración de la herramienta y sus prestaciones}

En cuanto a la valoración de la herramienta y las prestaciones que tiene, los alumnos la consideraron de forma positiva. A continuación, presentamos detalladamente los resultados:

E1 90\% de los alumnos expresó que Pixton le gustó para aprender en clase de Geografía: muchísimo en el 30\% de los casos, mucho en el 35\% y bastante al $25 \%$. Todos ellos valoraron Pixton como una herramienta fácil de usar, un $15 \%$ afirmó que lo fue muchísimo, un 30\% que mucho y un 55\% que bastante. En cuanto a la percepción de haber sido una actividad divertida, la gran mayoría de los participantes (95\%) afirmó que se habían divertido con la actividad, solo le pareció poco divertida a un $5 \%$. En relación a la opción de subir imágenes a la herramienta para crear el cómic, a un $45 \%$ le gustó muchísimo, a un 50\% mucho y al 5\% bastante. En cuanto a la posibilidad de crear personajes, pudiendo elegir y editar sus expresiones, posturas, pelo y vestuario, el $65 \%$ de los alumnos dijo que le gustó muchísimo y el $25 \%$ que mucho, siendo un $90 \%$ de la clase. En suma, la valoración general que los participantes hicieron de la actividad y el uso de Pixton es muy positiva. 


\subsection{Sobre el material complementario}

En relación a cuánto les gustó el material diseñado y elaborado especialmente para la actividad, el $40 \%$ de los alumnos manifestó que le gustó muchísimo y el $35 \%$ que mucho, siendo el representativo $75 \%$ de los alumnos el que ha dado los valores más positivos. Atendiendo al grado de utilidad de trabajar con los mapas y las imágenes, un $45 \%$ respondió que lo fue muchísimo, un $30 \%$ que mucho, y el $25 \%$ restante valoró que bastante. A la gran mayoría de los estudiantes, un amplísimo 95\%, constató que le fue de gran utilidad la entrega del material de la carpeta impreso y que le gustó tenerlo físicamente: el $25 \%$ de lo alumnos dijo que le gustó muchísimo, un $40 \%$ que mucho y a un 30\% le gustó bastante. La totalidad de los alumnos afirmó que la hoja de planificación les sirvió de ayuda para elaborar sus cómics: el 25\% afirmó que muchísimo y el $45 \%$ que mucho, siendo el $70 \%$ de los alumnos. Otro 30\% valoró que le sirvió de bastante ayuda. Sobre el pendrive que fue entregado a cada grupo, junto a la carpeta de trabajo para agilizar y ahorrar tiempo con descargas y poder avanzar así en el desarrollo de la actividad, todos coincidieron en afirmar que fue una buena idea.

\section{Conclusiones}

Tras llevar a cabo la investigación, en relación a los interrogantes que nos plantemos al inicio, podemos afirmar que (1) el cómic es muy válido para aprender lengua y geografía de forma lúdica, práctica y significativa como apuntan los datos expuestos; (2) existe un gran número de herramientas TIC para la creación de cómics, pero solo 3 de las 44 analizadas cumplían los ítems mínimos necesarios para la propuesta didáctica (estar en español, permitir la subida de imágenes y ser propiamente una herramienta TIC con este fin); (3) se extrae que es posible realizar actividades cooperativas, comunicativas, creativas y lúdicas mediante Pixton, como "Lugares mágicos de España"; (4) la profesora titular del curso mostró motivación e interés por incluir actividades innovadoras en su programación y valoró muy positivamente la experiencia, ofreciendo su colaboración para volver a desarrollarla empleando más tiempo para su realización e incluso diseñar nuevas actividades en esta línea.

Por otra parte, además, en relación a la propuesta didáctica se considera que: 1) se ha conseguido el objetivo principal y los específicos, 2) la intervención facilitó el aprendizaje del español, como afirman las diferentes valoraciones sobre la actividad y el material; 3) los alumnos aprendieron mucho sobre aspectos lingüísticos y vocabulario específico, 4) valoraron muy positivamente el material considerándolo muy práctico y manipulable, destacando el uso de mapas por permitir conocer características sobre los lugares y ver su ubicación e imágenes al mismo tiempo; 5) conocieron aspectos y vocabulario del relieve de estos lugares y sus proximidades, 6) fue una actividad con un altísimo grado de creatividad, por las posibilidades que ofrece al crear la historia, los personajes y los escenarios, 7) expresaron haber aprendido mucho sobre los lugares que consultaron en los documentos, manifestando que poder consultar las imágenes les resultó muy útil para crear conceptos más amplios y reales, al no tener que imaginarlos únicamente al leer sobre ellos; 8) aprendieron y contextualizaron expresiones idiomáticas sobre el clima, aun siendo material complementario; y 9) la gran mayoría valoró Pixton como una herramienta de uso muy sencillo.

En resumen, los resultados obtenidos revelan la eficacia de la metodología, los materiales y recursos utilizados y la viabilidad de Pixton para la enseñanza del español. 


\section{Bibliografía}

Instituto Cervantes (2006). Plan Curricular del Instituto Cervantes. Madrid: Biblioteca Nueva. Recuperado el 02/10/17, de: https://cvc.cervantes.es/ENSENANZA/biblioteca_ele/plan_curricular/niveles/0 7 _generos_discursivos_inventario_b1-b2.htm

JimÉnez PAlmero, D., Mora NúÑEZ, M., CuAdros MUÑOZ, R. (2016). «La importancia de las nuevas tecnologías en el proceso educativo. Propuesta didáctica TIC para ELE: "melendien7dias"». Revista Fuentes, 18 (2), 209-223. DOI: http://dx.doi.org/10.12795/revistafuentes.2016.18.2.07

Lorente Rebollo, Tomás (1990). «El lenguaje del Cómic». Didáctica (Lengua y literatura), 2, 141-160. Recuperado el 21/10/17, de: https://dialnet.unirioja.es/servlet/articulo?codigo $=906204$

Luque Gil, Ana María y NAVArro JuRAdo, Enrique (2011). «El aprendizaje cooperativo y la enseñanza de geografía en el marco de EEES». Revista Didáctica Geográfica, 12, 52-58. Recuperado el 06/1/18, de: http://www.agegeografia.es/didacticageografica/index.php/didacticageografica/article/viewFile/58/58

MECD (2002). Marco común europeo de referencia para las lenguas: aprendizaje, enseñanza y evaluación. Madrid: Dirección General del MECD, Subdirección General de Información y Publicaciones Anaya. Recuperado el 01/10/17, de: https://cvc.cervantes.es/ensenanza/biblioteca_ele/marco/cvc_mer.pdf

MORA TERUEL, Francisco. (2016). Neuroeducación. Madrid: Alianza Editorial.

Nieto Martín, Santiago (2010). «Paradigmas, características y modalidades de la investigación en educación». En S. Nieto (Ed.), Principios, métodos y técnicas esenciales para la investigación educativa (pp.79-91). Madrid: Dykinson.

ORTIZ MOYA, José (2009). «El cómic como recurso didáctico en Educación Primaria». Temas para la Educación: revista digital para profesionales de la enseñanza, 5, 1-6.

PIXTON COMICS (2018). Pixton para Escuelas. Recuperado el 20/9/17, de: https://www.pixton.com/es/

PUjOLÀS MASET, Pere (2012). «Aulas inclusivas y aprendizaje cooperativo». Educatio Siglo XXI, 30 (1), 89-102. Recuperado el 11/11/17, de: http://revistas.um.es/educatio/article/view/149151/132141

REAl ACADEMIa EsPañola (2017). Diccionario de la Lengua Española. Recuperado el 23/8/18, de: http://dle.rae.es/?id=9vpr4Ha

RoBInSOn, Ken (2011). Busca tu elemento. Aprende a ser creativo individual y colectivamente. Barcelona: Empresa Activa.

VillarRuBia ZúÑIGA, Marisol (2009). Crear un cómic en el aula de ELE. Instituto Cervantes de Leeds. Recuperado el 23/8/17, de: https://cvc.cervantes.es/ensenanza/biblioteca_ele/publicaciones_centros/PDF/ $\% 20$ ma\%20nchester_2009/12_villarrubia.pdf 